\title{
openheart Real-world comparison of clopidogrel, prasugrel and ticagrelor in patients undergoing primary percutaneous coronary intervention
}

\author{
Arvindra Krishnamurthy, ${ }^{\oplus 1,2}$ Claire Keeble, ${ }^{1}$ Michelle Anderson, ${ }^{2}$ Kathryn Somers, ${ }^{2}$ \\ Natalie Burton-Wood, ${ }^{2}$ Charlotte Harland, ${ }^{2}$ Paul Baxter, ${ }^{1}$ Jim McLenachan, ${ }^{2}$ \\ Jonathan Blaxill, ${ }^{2}$ Daniel J Blackman, ${ }^{2}$ Christopher Malkin, ${ }^{2}$ Stephen Wheatcroft, ${ }^{1,2}$ \\ John Greenwood ${ }^{1,2}$
}

To cite: Krishnamurthy A, Keeble C, Anderson M, et al. Real-world comparison of clopidogrel, prasugrel and ticagrelor in patients undergoing primary percutaneous coronary intervention. Open Heart 2019;6:e00951. doi:10.1136/ openhrt-2018-000951

Received 12 October 2018 Accepted 30 May 2019

\section{Check for updates}

(c) Author(s) (or their employer(s)) 2019. Re-use permitted under CC BY-NC. No commercial re-use. See rights and permissions. Published by BMJ.

\section{${ }^{1}$ Leeds Institute of}

Cardiovascular and Metabolic Medicine, University of Leeds, Leeds, UK

${ }^{2}$ Department of Cardiology, Leeds General Infirmary, Leeds, UK

\section{Correspondence to} Dr Arvindra Krishnamurthy; arvindra@doctors.org.uk

\section{ABSTRACT}

Background There is a paucity of real-world outcome data comparing clopidogrel, prasugrel and ticagrelor in primary percutaneous coronary intervention (PPCl) for ST-segment elevation myocardial infarction (STEMI). We sought to assess the association of choice of oral P2Y12receptor inhibitor with clinical outcomes following PPCl for STEMI in a large consecutive patient series.

Methods Demographic, procedural and 12-month outcome data were prospectively collected for all patients undergoing PPCI in Leeds, UK, between 01 January 2009 and 31 December 2011, and 01 January 2013 and 31 December 2013. Clinical endpoints were 30-day and 12-month all-cause mortality, recurrent MI and 30-day HORIZONS-major bleeding. Logistic regression analyses were undertaken to adjust for confounding factors.

Results Prasugrel $(n=1244)$ was associated with lower adjusted 30-day (OR $0.53(0.34-0.85)$ ) and 12-month (OR 0.55 (0.38-0.78)) mortality, and 12-month MI (OR $0.63(0.42-0.94))$ compared with clopidogrel $(n=1648)$. Importantly, prasugrel was associated with lower adjusted 30-day mortality (OR $0.51(0.29-0.91))$ compared with ticagrelor $(\mathrm{n}=811)$. Lower 30-day (OR $0.40(0.17-0.94))$ and 12-month (OR 0.54 (0.32-0.93)) Ml were observed in ticagrelor compared with clopidogrel, an association absent in comparison with prasugrel. Adjusted bleeding were not statistically significantly different among the P2Y12-receptor inhibitors.

Conclusion In this large consecutive real-world series, prasugrel was associated with lower adjusted 30-day mortality compared with ticagrelor and clopidogrel, and lower adjusted 12-month mortality compared with clopidogrel. Both prasugrel and ticagrelor were associated with lower recurrent MI following PPCl compared with clopidogrel, with no overall increase in adjusted bleeding.

\section{INTRODUCTION}

Primary percutaneous coronary intervention (PPCI) is the guideline-recommended treatment strategy for patients presenting with ST-segment elevation myocardial infarction (STEMI). ${ }^{12}$

\section{Key questions}

What is already known about this subject?

- Ticagrelor and prasugrel have both been shown to be beneficial when used in patients with acute coronary syndromes. However, there is little available data to guide clinicians in choosing between these newer agents in primary percutaneous coronary intervention (PPCl).

What does this study add?

- The main finding of this study was that prasugrel was associated with lower risk-adjusted mortality compared with both clopidogrel and ticagrelor, in patients undergoing PPCl. Both prasugrel and ticagrelor were associated with lower recurrent myocardial infarction compared with clopidogrel. There were no significant differences in bleeding among the three groups.

How might this impact on clinical practice?

- The findings of this study suggest that the use of prasugrel and ticagrelor in PPCl could lead to improved outcomes compared with clopidogrel. The difference in outcomes noted between prasugrel and ticagrelor may influence prescribing choice in selected patients, until further data are published from randomised controlled trials.

The addition of oral platelet P2Y12 ADP receptor inhibitors to aspirin has been shown to significantly reduce adverse events following PCI. ${ }^{3-6}$ Therefore, dual-antiplatelet therapy (DAPT) in PPCI for STEMI has been recommended for use periprocedurally and postprocedurally up to a minimum of 12 months. ${ }^{27}$ Despite evidence of significant difference in platelet reactivity in patients treated with prasugrel compared with ticagrelor, there have been only two observational studies and one meta-analysis comparing clinical outcomes of patients treated with 
prasugrel with clinical outcomes of patients treated with ticagrelor in STEMI, with contrasting results. ${ }^{8-11}$ In terms of randomised controlled trials (RCTs), the PRAGUE-18 study which aimed to compare prasugrel with ticagrelor was terminated early due to futility and ISAR-REACT 5 is still ongoing. ${ }^{12} 13$

The aim of this prospective outcomes study was to obtain 'real-world' data from a large consecutive patient series, to facilitate comparison of clinical outcomes of patients treated with clopidogrel, prasugrel and ticagrelor when undergoing PPCI.

\section{METHODS}

The West Yorkshire PPCI Outcome Study was established as a prospective, observational study to ascertain procedural and demographic characteristics, and clinical outcomes in all patients undergoing PPCI for STEMI at Leeds General Infirmary (LGI), UK. LGI is the largest single-centre PPCI centre by volume in the UK, providing a 24/7 PPCI service to a catchment population of 3.2 million people. The period of recruitment was from 1st of January 2009 until 31st of December 2011, and 1st of January 2013 until 31st of December 2013 (4 calendar years). Patients who presented between 01 January 2012 and 31 December 2012 were not included as follow-up, and data input were not possible due to limited staff availability at the time.

Primary endpoints were 30-day and 12-month all-cause mortality. Secondary endpoints were 30-day and 12-month MI, and 30-day major bleeding by HORIZONS criteria ${ }^{14}$ (defined as intracranial or intraocular bleeding; access site bleeding of diameter of $\geq 5 \mathrm{~cm}$, or requiring intervention; a reduction in haemoglobin of $\geq 40 \mathrm{~g} / \mathrm{L}$ without an overt source of bleeding, or $\geq 30 \mathrm{~g} / \mathrm{L}$ with an overt source of bleeding; re-operation for bleeding and blood transfusion).

Patients who presented with chest pain consistent with myocardial ischaemia for a minimum of $20 \mathrm{~min}$ with ST-segment elevation of $\geq 1 \mathrm{~mm}$ in contiguous limb leads and/or $\geq 2 \mathrm{~mm}$ in contiguous chest leads, or with presumed new left bundle branch block on a 12-lead ECG were diagnosed with STEMI and were included in this study. Patients were transferred by paramedics directly to the cardiac catheter laboratories in LGI after first medical contact, with a telephone referral en route to minimise prehospital delays. ${ }^{15}$ Emergency diagnostic coronary angiography with (if indicated) follow-on PPCI was undertaken if patients presented within 12 hours of symptom onset. Oral aspirin $300 \mathrm{mg}$ (administered at the point of diagnosis usually in the prehospital setting) and either $600 \mathrm{mg}$ clopidogrel, $60 \mathrm{mg}$ prasugrel or 180 $\mathrm{mg}$ oral ticagrelor (administered in the cardiac catheterisation laboratory prior to PPCI, with the exception of patients who were referred from surrounding emergency departments, who received their P2Y12-receptor inhibitor prior to transfer to the cardiac catheterisation laboratories) were administered preprocedure, depending on guideline recommendations at the time of index PPCI. Either bivalirudin or unfractionated heparin $( \pm$ bail out glycoprotein IIb/IIIa inhibitor) were administered during PPCI. Arterial access site, choice of stent (drugeluting stent (DES) or bare-metal stent (BMS)) and aspiration thrombectomy were at the operator's discretion. Thrombolysis in MI (TIMI) classification was used to grade preprocedure and postprocedure flow in the infarct-related artery. Call-for-help time (call time) and time of patient arrival at LGI (door time) were obtained either from the ambulance reports or if patients self-presented from the emergency department triage notes. Time to first interventional device (balloon time) was obtained from the electronic cardiac catheter laboratory report. Patients were observed on the coronary care unit post-PPCI for a minimum of 24 hours, and remained in the hospital for a minimum of 72 hours (either at LGI if patients were local, or re-patriated to the nearest district general hospital after a minimum of 6 hours observation). DAPT, statin therapy, beta-adrenergic receptor blockers, ACE inhibitors (or angiotensin II receptor blockers) and (if indicated) mineralocorticoid receptor antagonists were prescribed according to guideline recommendation.

\section{Follow-up}

Written and electronic case notes were reviewed at the time of discharge to ascertain patient characteristics, procedural variables and in-hospital outcomes. Drug therapy and adverse events were identified up to a minimum of 12 months following index PPCI by a combination of patient telephone contact, accessing clinical information via written or electronic hospital records or from the responsible primary care physician. Mortality data up to a minimum of 12 months post-PPCI were obtained from the Office of National Statistics and central National Health Service (NHS) records. The Myocardial Infarction National Audit Project (MINAP) database (database with information pertaining to all patients admitted acutely into NHS hospitals in England and Wales with unstable angina, non-STEMI and STEMI) was used to identify MIs. Review of hospital discharge and clinic letters, and hospital electronic pathology servers (for a rise in creatine kinase and/or troponin, and drops in haemoglobin) were undertaken to verify MIs and bleeding. Event adjudication was undertaken by blinded clinicians in consensus.

\section{Statistical analysis}

Data checking and validation were undertaken to ensure the accuracy and validity of values obtained, and summary statistics were generated. All analyses were performed in IBM SPSS V.23.0.0.2. Records with incomplete data collection were excluded from the analyses. Results were analysed according to P2Y12-receptor inhibitor treatment at LGI. Continuous variables were reported as medians with their corresponding IQR. Categorical variables were reported as frequencies with their 
corresponding percentages (n (\%)). Categorical variables were compared using $\chi^{2}$ tests. Continuous variables were compared using independent samples Student's t-tests and Mann-Whitney $\mathrm{U}$ tests, as appropriate. A two-sided $\mathrm{p}$ value of $\leq 0.05$ was considered statistically significant.

Multivariable logistic regression was used to correct for confounding variables, and all ORs from the logistic regression models were reported with 95\% CIs. Variables included in the logistic regression models were: P2Y12-receptor inhibitor, diabetes mellitus, hypertension, hypercholesterolaemia, renal dysfunction, prior MI, anterior MI, peripheral vascular disease or cerebrovascular disease, age above 65 years, radial artery access, call-to-balloon time of above $120 \mathrm{~min}$, glycoprotein IIb/IIIa antagonist use, presentation with cardiogenic shock, year PPCI was performed and DES implantation. These variables were selected as known confounders, and exploratory analyses revealed that all of them had $p$ values of $\leq 0.10$.

\section{RESULTS}

A total of 4056 patients underwent PPCI during the recruitment period. Baseline, clinical and follow-up data were available for $3703(91.3 \%)$ patients who were included in the analysis. Data for 30-day and 12-month mortality, as well as 30-day and 12-month MI, were available for all included patients. Data for 30-day bleeding were available for $3449(93.1 \%)$ of the 3703 patients, who were included in the analysis.

A total of $1648(44.5 \%)$ patients received clopidogrel, $1244(33.6 \%)$ patients received prasugrel and 811 (21.9\%) patients received ticagrelor as their P2Y12-receptor inhibitor. There were multiple statistically significant differences in baseline and procedural variables (table 1). The temporal trends of use of each P2Y12-receptor inhibitor over the study period are shown in figure 1. Unadjusted and adjusted rates of 30-day and 12-month mortality, recurrent MI and 30-day bleeding are listed in table 2.

\section{Prasugrel versus ticagrelor}

Statistically significant differences in unadjusted and adjusted 30-day mortality were observed in the comparison of prasugrel with ticagrelor, favouring patients receiving prasugrel. Although unadjusted 12-month mortality was lower in patients receiving prasugrel, multivariable analysis revealed no statistically significant difference in adjusted 12-month mortality between the two groups. Unadjusted and adjusted 30-day bleeding were not statistically significantly different between the two groups either (table 2).

\section{Prasugrel versus clopidogrel}

Comparison of prasugrel and clopidogrel revealed statistically significant differences in unadjusted and adjusted mortality, both at 30 days and 12 months, with both endpoints being statistically significantly lower in patients receiving prasugrel, compared with patients receiving clopidogrel. Unadjusted and adjusted 30-day MI, and adjusted 12-month MI were statistically significantly lower in patients receiving prasugrel compared with clopidogrel. Unadjusted and adjusted rates of 30-day bleeding were not statistically significantly different between the two groups (table 2).

\section{Ticagrelor versus clopidogrel}

Unadjusted and adjusted 30-day and 12-month mortality, and 30-day major bleeding were not statistically significantly different between the two groups. However, unadjusted and adjusted 30-day and 12-month MI were statistically significantly less likely in patients receiving ticagrelor compared with clopidogrel (table 2).

\section{DISCUSSION}

Our analysis of real-world data from a large consecutive patient series from a UK tertiary cardiac centre has provided an important head-to-head clinical comparison between prasugrel and ticagrelor in the setting of PPCI for STEMI, with the first direct comparison of bleeding between ticagrelor and prasugrel. We have also compared prasugrel and ticagrelor individually with clopidogrel. Patients treated with prasugrel in this series were found to have a statistically significantly lower adjusted 30-day and 12-month mortality compared with those treated with clopidogrel, a finding which was not observed in the ticagrelor cohort compared with clopidogrel. Importantly, we have shown for the first time that patients receiving prasugrel had lower adjusted 30-day mortality compared with ticagrelor, a finding which approached, but did not reach statistical significance at 12 months $(p=0.06)$. Both prasugrel and ticagrelor were associated with lower adjusted MI compared with clopidogrel, with ticagrelor being statistically significantly different at both 30 days and 12 months. We did not observe any difference in adjusted bleeding among the three P2Y12-receptor inhibitors.

Olier et al compared survival of $>89000$ patients according to P2Y12-receptor inhibitor therapy, and found that in patients undergoing PPCI, treatment with prasugrel was associated with lower mortality compared with ticagrelor or clopidogrel, with no significant difference observed between ticagrelor and clopidogrel. ${ }^{10}$ The main finding in our study, that prasugrel use was associated with better outcomes compared with ticagrelor and clopidogrel, was in keeping with their results. Contrary to RCT findings, their study found that in-hospital bleeding was significantly lower with prasugrel and ticagrelor compared with clopidogrel, despite prior studies suggesting that the third-generation P2Y12-receptor inhibitors were more potent at platelet inhibition. However, in addition to mortality, our study compared rates of recurrent MI and 30-day bleeding, which are both important factors to consider in comparisons of P2Y12-receptor inhibitor therapy.

In comparison to the analysis by Gosling $e t a l,{ }^{9}$ we $\mathrm{did}$ not observe a reduction in mortality in patients treated 


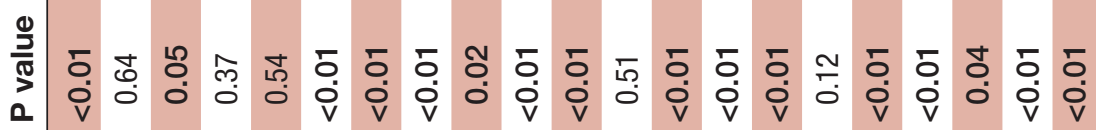

$\overline{1}$

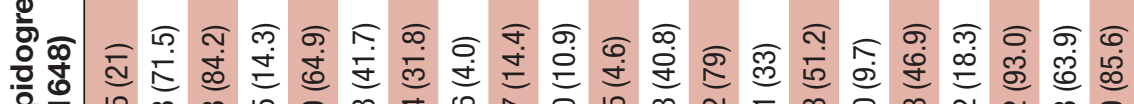

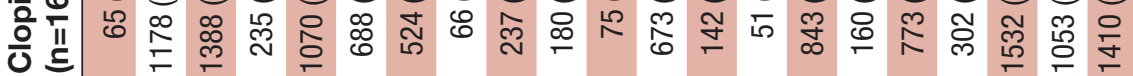

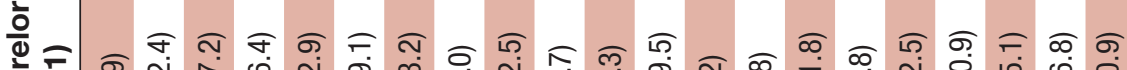

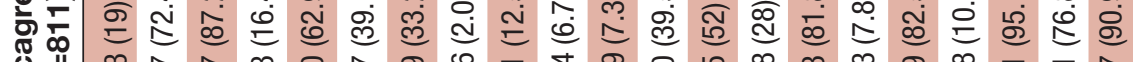
光

㓂 a

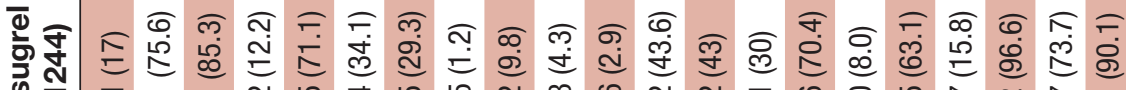
至

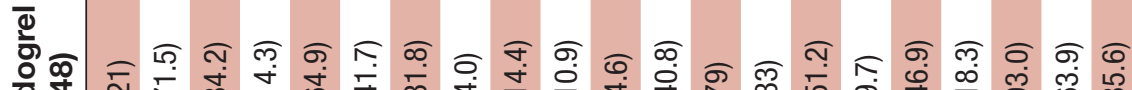

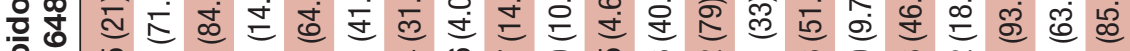

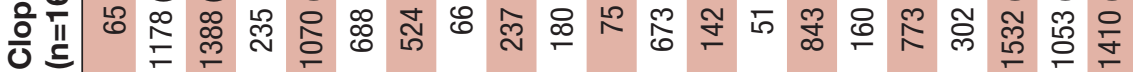

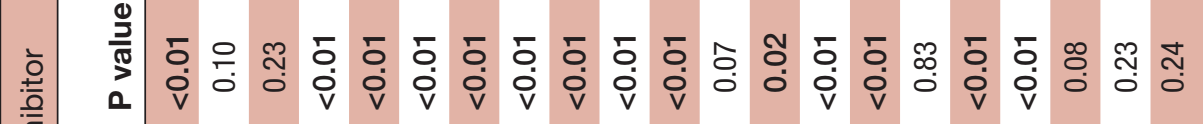
휴 व ᄒ⿱丷⿹弔㇒ 诲

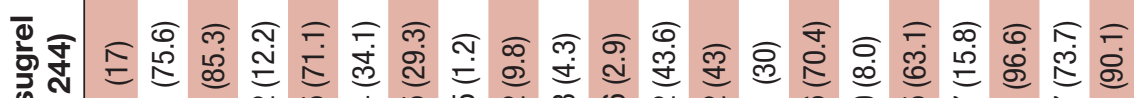

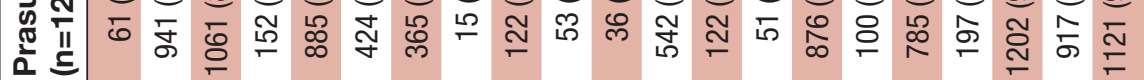

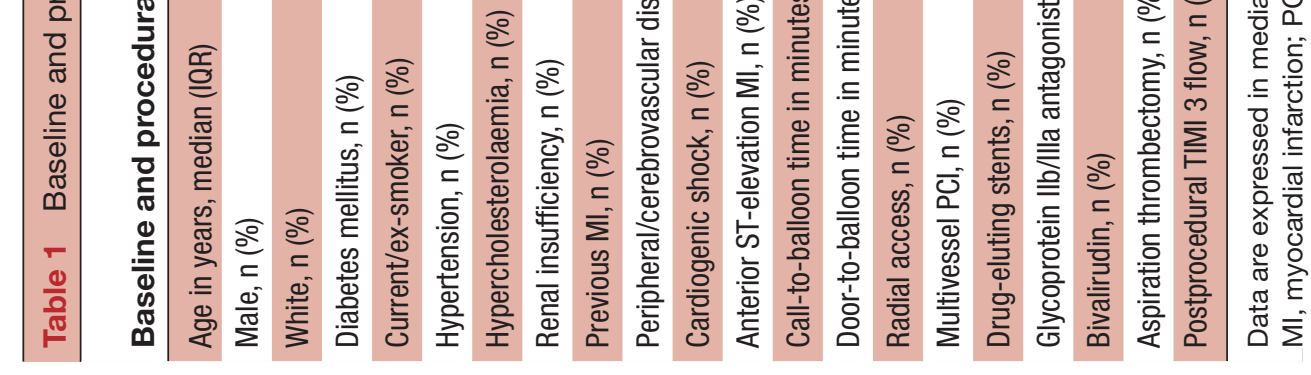


1200

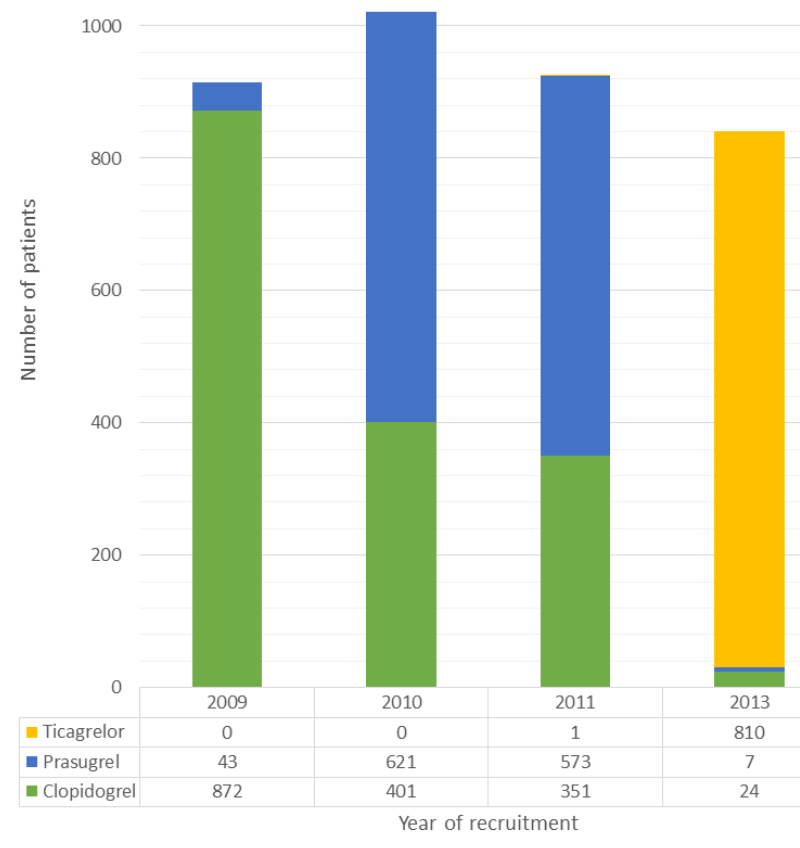

Figure 1 P2Y12-receptor inhibitor administration over the study period.

with ticagrelor compared with clopidogrel. We found that prasugrel was associated with reduced mortality at 30 days and 12 months compared with clopidogrel, and at 30 days compared with ticagrelor, which was partly in keeping with their findings. In their study, although, 30-day outcomes were not presented, a signal towards lower 12-month mortality in patients receiving prasugrel compared with ticagrelor was observed (HR 0.81 (0.61-1.10)). Key differences in statistical analyses might account for the differences in findings. Gosling et al did not present or adjust for arterial access site, which could have been different between the groups if there was a temporal trend in the use of relevant P2Y12-receptor antagonist. Radial artery access was included in our regression models, and was found to be an independent predictor of outcomes, with lower adjusted 30-day (OR $0.28(0.19-0.40))$ and 12-month (OR 0.50 $(0.38-0.66))$ mortality, and 30-day bleeding (OR 0.40 $(0.28-0.56))$ compared with femoral artery access. Arterial access site is an important variable to correct for considering the wealth of evidence showing that transradial PPCI is independently associated with improved clinical outcomes compared with transfemoral PPCI. ${ }^{16-24}$ We had also adjusted for year of presentation, to try to correct for potential unrecorded confounders, such as progress with DES platforms and importantly, non-pharmacological secondary prevention. Our key finding, that the third-generation P2Y12-receptor inhibitors were associated with better outcomes compared with clopidogrel, was in keeping with their study.

Koshy et $a l^{25}$ compared 12-month mortality in prasugrel and clopidogrel, and reported that patients receiving prasugrel had lower adjusted 12-month mortality compared with patients receiving clopidogrel. It is, however, important to note that patients who received prasugrel in their analysis were more likely to have undergone transradial PPCI compared with patients who received clopidogrel $(78.0 \%$ vs $61.4 \%)$. However, in contrast to our study, choice of arterial access site was not included in their multivariable analysis. Postprocedural TIMI 3 flow was also included in their Cox model, which we did not include in our regression model, as it was plausible that P2Y12-receptor inhibitors could influence post-PPCI microvascular function. ${ }^{26}$ Patient age and door-to-balloon times also appeared different between our study

Table 2 Comparison of clinical outcomes between P2Y12-receptor inhibitors

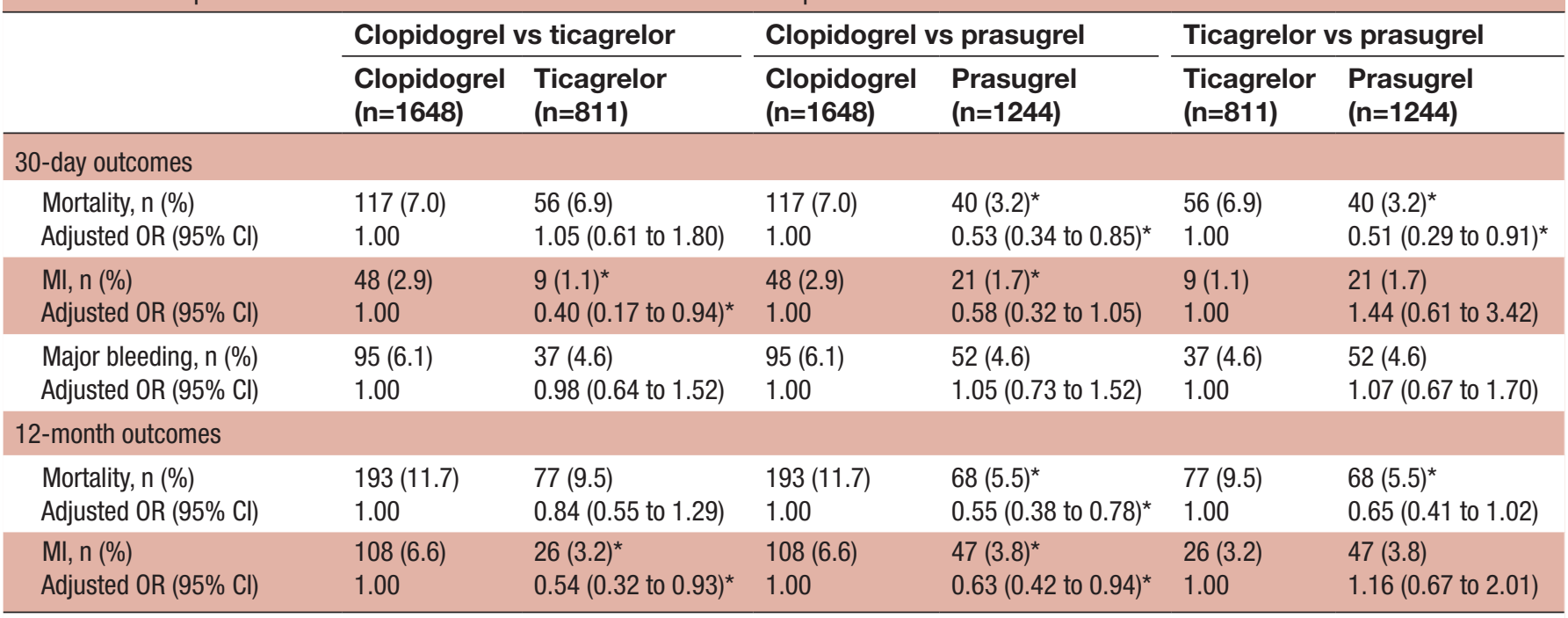

Data are expressed in $\mathrm{n}(\%)$.

${ }^{*} P$ value $\leq 0.05$.

MI, myocardial infarction. 
and Koshy et als, and higher rates of glycoprotein IIb/ IIIa inhibitor use was observed in both subgroups of their study compared with our study. Importantly, despite the difference in statistical analysis, along with differences in baseline and procedural characteristics, a similar association between prasugrel and survival was observed in both studies, with the additional finding of an inverse association between prasugrel and 12-month recurrent MI observed in our analysis.

There were several differences between the findings of our study and that of TRITON-TIMI $38 .{ }^{27} 28$ We observed lower 30-day and 12-month mortality in patients treated with prasugrel compared with clopidogrel. We also observed lower rates of recurrent MI within 12 months of index PPCI in patients receiving prasugrel compared with clopidogrel, which was in keeping with their findings. There were important differences in baseline and procedural characteristics between the PPCI subgroup of TRITON-TIMI 38 and our study that could explain these differences. The patients in our study appeared older (median age 62 vs 59) and had higher prevalence of tobacco use $(67.5 \%$ vs $45.0 \%)$, but a lower prevalence of diabetes mellitus ( $14.3 \%$ vs $16.8 \%$ ), hypertension $(38.0 \%$ vs $48.7 \%)$ and hypercholesterolaemia (32.1\% vs $37.6 \%)$. The patients included in our study were also more likely to receive DESs $(60.1 \%$ vs $28.5 \%$ ), were predominantly anticoagulated with bivalirudin $(95.5 \%$ vs $1.0 \%)$ and were less likely to receive glycoprotein IIb/IIIa inhibitor ( $85.3 \%$ vs $66.2 \%$ ) compared with the patients in TRITON TIMI 38. Our analysis of 30-day bleeding was in keeping with this study, which also found no statistically significant difference in bleeding at 30 days.

In a subgroup analysis from the PLATO investigators of patients with STEMI intended for management by PPCI, ${ }^{29}$ all-cause mortality reduction in patients treated with ticagrelor compared with patients treated with clopidogrel approached statistical significance $(p=0.05)$ at 12 months, a finding that we did not observe in this study. The main statistically significant differences in outcomes were a reduction in vascular mortality, MI and stent thrombosis at 12 months for ticagrelor compared with clopidogrel. Conversely, an increased risk of stroke was noted in patients treated with ticagrelor. In our study, we found that patients treated with ticagrelor had lower rates of recurrent MI at 30 days and 12 months compared with patients treated with clopidogrel. We found that patients treated with ticagrelor did not have a higher rate of bleeding compared with patients treated with clopidogrel, in keeping with the PLATO substudy analysis. There were, however, important differences in clinical characteristics between the PLATO substudy and our study population that could account for the differences observed. In the PLATO substudy, patients who received open-label clopidogrel prerandomisation were then given an additional $600 \mathrm{mg}$ loading dose of clopidogrel on randomisation (if randomised to clopidogrel). The majority of their patients received BMSs instead of DESs, and procedural anticoagulation was mainly achieved with unfractionated heparin, rather than bivalirudin, with higher use of glycoprotein IIb/IIIa inhibitor in comparison with our study population.

In our study, there were significant differences in baseline and procedural characteristics between the three groups of patients (table 1). There was a temporal change in the use of individual P2Y12-receptor inhibitors over the study period (figure 1). In 2009, the majority of patients undergoing PPCI in LGI received clopidogrel, with the remainder receiving prasugrel. In 2010 and 2011, the majority of patients received prasugrel and in 2013, the majority of patients received ticagrelor. During this period, there were changes in the rates of transradial PPCI (39.6\% in 2009 vs $81.8 \%$ in 2013) and the use of DESs $(41.3 \%$ in 2009 vs $82.2 \%$ in 2013). As a result of lower thresholds for accepting patients for PPCI, a higher proportion of patients in the ticagrelor cohort underwent PPCI for cardiogenic shock, which is traditionally regarded as a marker of poor prognosis. ${ }^{30}$ There were also advances in secondary prevention over the study period, including an increased rate of implantation of primary-prevention implantable cardioverter-defibrillator devices. ${ }^{31}$ These and other confounders, such as changes in clinical practice, improvements in operator proficiency and improvements in the PPCI pathway, could have all contributed to the differences in unadjusted outcomes. However, multivariable analysis, including adjustment for year of PPCI to adjust for unquantifiable time-dependent confounders, was undertaken to correct for major confounding factors.

\section{LIMITATIONS}

As this was a single-centre observational study, our findings might not reflect the broader population. However, our study demographics are comparable to those in the UK Myocardial Ischaemia National Audit Project (MINAP). Our practice and outcomes might not reflect those in other regions, as regional differences in STEMI management have been reported. ${ }^{32}$ We were unable to correct for Killip class. However, with this study being an 'all-comers' study, we have no reason to believe that there would be statistically significant differences in Killip class between the groups. There have been many advances in procedural techniques and technologies over the years such that we were not able to correct for the generation of DES used in each subgroup, which potentially could have affected outcomes. However, we tried to correct for these by adjusting for the year of admission. As this was an observational study, the study populations were unmatched. However, multivariable analyses were undertaken to adjust for major confounders. Perhaps most importantly we were unable to fully ascertain continuation and/or switching of P2Y12-receptor inhibitors following discharge, but this limitation was also present in the only other comparable real-world studies. ${ }^{9} 1025$ Switching from ticagrelor was noted in PLATO due to dyspnoea, but also perhaps due to compliance with its 
two times per day administration. However, in our study, differences in outcomes were observed in all three comparisons of P2Y12-receptor inhibitors, which should not have been observed if switching of P2Y12-receptor inhibitor therapy influenced differences in outcomes. Event rates in this study were low compared with PLATO or TRITON-TIMI 38 that involved larger numbers of patients, as under-reporting of adverse events is more likely in observational studies compared with RCTs, and therefore play of chance could not be excluded. We were also unable to obtain details of other changes to secondary prevention (aspirin, beta-adrenergic receptor blockers, ACE-inhibitors and statins) at 30 days and 12 months. However, they were unlikely to be different across the groups as they were all part of guideline-indicated care through the period of study. Finally, the findings observed in this study should be hypothesis-generating, and an adequately powered RCT may be able to reveal differences in outcomes between P2Y12-receptor inhibitors that might inform future guidelines pertaining to optimal DAPT strategy following PPCI.

\section{CONCLUSION}

In PPCI, treatment with prasugrel was independently associated with lower adjusted probabilities of 30-day and 12-month mortality, and 12-month MI compared with clopidogrel. Importantly, treatment with prasugrel was independently associated with lower adjusted 30-day mortality compared with ticagrelor. Although 30-day and 12-month MI were lower in patients treated with ticagrelor compared with clopidogrel, there were no significant differences in 30-day and 12-month mortality between patients treated with ticagrelor and clopidogrel. Overall, the third-generation P2Y12-receptor inhibitors were associated with lower adverse outcomes compared with clopidogrel, with no excess bleeding.

Funding The authors have not declared a specific grant for this research from any funding agency in the public, commercial or not-for-profit sectors.

Competing interests Daiichi Sankyo partially contributed to the overall postgraduate degree research fellowship salary of AK. AK, SW, JB, JM and CM have received honoraria from AstraZeneca for presentations. Neither company, in any capacity, have had access to or were involved in data collection and analysis, or the preparation of this manuscript.

Patient consent for publication Not required.

Ethics approval UK National Research Ethics Service approval (0911-11311/60) and NHS approval from each hospital within the region were obtained.

Provenance and peer review Not commissioned; externally peer reviewed.

Data availability statement The data for this study are available from the corresponding author, upon reasonable request.

Open access This is an open access article distributed in accordance with the Creative Commons Attribution Non Commercial (CC BY-NC 4.0) license, which permits others to distribute, remix, adapt, build upon this work non-commercially, and license their derivative works on different terms, provided the original work is properly cited, appropriate credit is given, any changes made indicated, and the use is non-commercial. See: http://creativecommons.org/licenses/by-nc/4.0/.

\section{REFERENCES}

1. O'Gara PT, Kushner FG, Ascheim DD, et al. 2013 ACCF/AHA guideline for the management of ST-elevation myocardial infarction: a report of the American College of cardiology Foundation/American Heart Association Task Force on practice guidelines. J Am Coll Cardiol 2013;61:e78-140.

2. Steg PG, James SK, Atar D, et al. ESC guidelines for the management of acute myocardial infarction in patients presenting with ST-segment elevation. Eur Heart J 2012;33:2569-619.

3. Schömig A, Neumann F-J, Kastrati A, et al. A randomized comparison of antiplatelet and anticoagulant therapy after the placement of coronary-artery stents. N Engl J Med 1996;334:1084-9.

4. Bertrand ME, Legrand V, Boland J, et al. Randomized multicenter comparison of conventional anticoagulation versus antiplatelet therapy in unplanned and elective coronary stenting. the full anticoagulation versus aspirin and ticlopidine (fantastic) study. Circulation 1998;98:1597-603.

5. Urban P, Macaya C, Rupprecht HJ, et al. Randomized evaluation of anticoagulation versus antiplatelet therapy after coronary stent implantation in high-risk patients: The Multicenter aspirin and ticlopidine trial after intracoronary stenting (MATTIS). Circulation 1998;98:2126-32.

6. Steinhubl SR, Berger PB, Mann JT, et al. Early and sustained dual oral antiplatelet therapy following percutaneous coronary intervention: a randomized controlled trial. JAMA 2002;288:2411-20.

7. Myocardial infarction with ST-segment elevation: acute management | 1-Recommendations | guidance and guidelines | NICE. Available: https://www.nice.org.uk/guidance/CG167/chapter/1Recommendations [Accessed 15 Jul 2016].

8. Alexopoulos D, Xanthopoulou I, Gkizas V, et al. Randomized assessment of ticagrelor versus prasugrel antiplatelet effects in patients with ST-Segment-Elevation myocardial infarction. Circ Cardiovasc Interv 2012;5:797-804.

9. Gosling R, Yazdani M, Parviz Y, et al. Comparison of P2Y ${ }_{12}$ inhibitors for mortality and stent thrombosis in patients with acute coronary syndromes: Single center study of 10793 consecutive 'real-world' patients. Platelets 2017;28:767-73.

10. Olier I, Sirker A, Hildick-Smith DJR, et al. Association of different antiplatelet therapies with mortality after primary percutaneous coronary intervention. Heart 2018;104:1683-90.

11. Rafique AM, Nayyar P, Wang TY, et al. Optimal P2Y12 inhibitor in patients with ST-Segment elevation myocardial infarction undergoing primary percutaneous coronary intervention: a network metaanalysis. JACC Cardiovasc Interv 2016;9:1036-46.

12. Motovska Z, Hlinomaz O, Miklik R, et al. Prasugrel versus ticagrelor in patients with acute myocardial infarction treated with primary percutaneous coronary intervention. Circulation 2016;134:1603-12.

13. Schulz S, Angiolillo DJ, Antoniucci D, et al. Randomized comparison of ticagrelor versus prasugrel in patients with acute coronary syndrome and planned invasive Strategy-Design and rationale of the intracoronary stenting and antithrombotic regimen: rapid early action for coronary treatment (ISAR-REACT) 5 trial. $J$ Cardiovasc Transl Res 2014;7:91-100.

14. Mehran R, Pocock SJ, Nikolsky E, et al. A risk score to predict bleeding in patients with acute coronary syndromes. J Am Coll Cardiol 2010;55:2556-66.

15. Dorsch MF, Greenwood JP, Priestley C, et al. Direct ambulance admission to the cardiac catheterization laboratory significantly reduces door-to-balloon times in primary percutaneous coronary intervention. Am Heart J 2008;155:1054-8.

16. Graham JJ, Yan AT, Tan MK, et al. Radial versus femoral access for percutaneous coronary intervention in ST-elevation myocardial infarction patients treated with fibrinolysis: results from the randomized routine early invasive clinical trials. Cardiovasc Revasc Med 2016;17:295-301.

17. Kilic S, Hermanides RS, Ottervanger JP, et al. Effects of radial versus femoral artery access in patients with acute myocardial infarction: a large centre prospective registry. Neth Heart J 2017;25:33-9.

18. Singh S, Singh M, Grewal N, et al. Transradial vs transfemoral percutaneous coronary intervention in ST-segment elevation myocardial infarction: a systemic review and meta-analysis. Can $J$ Cardiol 2016;32:777-90.

19. Kedev S, Sukmawan R, Kalpak O, et al. Transradial versus transfemoral access for female patients who underwent primary $\mathrm{PCl}$ in STEMI: two years follow-up data from acute STEMI interventional registry. Int J Cardiol 2016;217:S16-20.

20. Bauer T, Hochadel M, Brachmann J, et al. Use and outcome of radial versus femoral approach for primary $\mathrm{PCl}$ in patients with acute ST elevation myocardial infarction without cardiogenic shock: Results from the ALKK PCI registry. Cathet Cardiovasc Intervent 2015;86(Suppl 1):S8-S14. 
21. Rathod KS, Jones DA, Bromage DI, et al. Radial primary percutaneous coronary intervention is independently associated with decreased long-term mortality in high-risk ST-elevation myocardial infarction patients. J Cardiovasc Med (Hagerstown) 2014

22. Cantor WJ, Puley G, Natarajan MK, et al. Radial versus femoral access for emergent percutaneous coronary intervention with adjunct glycoprotein Ilb/llla Inhibition in acute myocardial infarction - the RADIAL-AMI pilot randomized trial. Am Heart $J$ 2005;150:543-9.

23. Généreux P, Mehran R, Palmerini T, et al. Radial access in patients with ST-segment elevation myocardial infarction undergoing primary angioplasty in acute myocardial infarction: the HORIZONS-AMI trial. Eurolntervention 2011;7:905-16.

24. Mamas MA, Ratib K, Routledge $\mathrm{H}$, et al. Influence of access site selection on PCl-related adverse events in patients with STEMI: meta-analysis of randomised controlled trials. Heart 2012;98:303-11.

25. Koshy A, Balasubramaniam K, Noman A, et al. Antiplatelet therapy in patients undergoing primary percutaneous coronary intervention for ST-elevation myocardial infarction: a retrospective observational study of prasugrel and clopidogrel. Cardiovasc Ther 2014;32:1-6.

26. Khan JN, Greenwood JP, Nazir SA, et al. Infarct size following treatment with second- versus third-generation P2Y ${ }_{12}$ antagonists in patients with multivessel coronary disease at ST-Segment elevation myocardial infarction in the CvLPRIT Study. J Am Heart Assoc 2016;5.

27. Wiviott $\mathrm{SD}$, Braunwald $\mathrm{E}, \mathrm{McCabe} \mathrm{CH}$, et al. Prasugrel versus clopidogrel in patients with acute coronary syndromes. N Engl J Med 2007;357:2001-15

28. Udell JA, Braunwald E, Antman EM, et al. Prasugrel versus clopidogrel in patients with ST-segment elevation myocardial infarction according to timing of percutaneous coronary intervention: a TRITON-TIMI 38 subgroup analysis (Trial to Assess Improvement in Therapeutic Outcomes by Optimizing Platelet Inhibition with Prasugrel-Thrombolysis In Myocardial Infarction 38). JACC Cardiovasc Interv 2014;7:604-12.

29. Steg PG, James S, Harrington RA, et al. Ticagrelor versus clopidogrel in patients with ST-elevation acute coronary syndromes intended for reperfusion with primary percutaneous coronary intervention: A Platelet Inhibition and Patient Outcomes (PLATO) trial subgroup analysis. Circulation 2010;122:2131-41.

30. Bengtson JR, Kaplan AJ, Pieper KS, et al. Prognosis in cardiogenic shock after acute myocardial infarction in the interventional era. $J$ Am Coll Cardiol 1992;20:1482-9.

31. Murgatroyd F. National audit of cardiac rhythm management devices, 2014: 239.

32. Herrett $\mathrm{E}$, Smeeth $\mathrm{L}$, Walker $\mathrm{L}$, et al. The myocardial ischaemia national audit Project (MINAP). Heart 2010;96:1264-7. 


\section{Correction: Real-world comparison of clopidogrel, prasugrel and ticagrelor in patients undergoing primary percutaneous coronary intervention}

Krishnamurthy A, Keeble C, Anderson M, et al. Real-world comparison of clopidogrel, prasugrel and ticagrelor in patients undergoing primary percutaneous coronary intervention. Open Heart 2019;6:e000951.

The published version misspelled co-author's name as John Greenwood. The correct name should be John P Greenwood.

Open access This is an open access article distributed in accordance with the Creative Commons Attribution Non Commercial (CC BY-NC 4.0) license, which permits others to distribute, remix, adapt, build upon this work non-commercially, and license their derivative works on different terms, provided the original work is properly cited, appropriate credit is given, any changes made indicated, and the use is non-commercial. See: http://creativecommons.org/licenses/by-nc/4.0/.

C Author(s) (or their employer(s)) 2019. Re-use permitted under CC BY-NC. No commercial re-use. See rights and permissions. Published by BMJ.

Open Heart 2019;6:e000951corr1. doi:10.1136/openhrt-2018-000951corr1

A) Check for updates 